\title{
Olympic Champion Sara Simeoni Talks about Gender Barriers in Sport and Medicine: Culture, Opportunities and Resources
}

\author{
Sara Simeoni ${ }^{1,2}$ and Daniela Catalano ${ }^{3, *}$ \\ 1 Movement Sciences and Sport Activities, University of G.D'Annunzio, 66100 Chieti-Pescara, Italy; \\ sara201@tiscali.it \\ 2 Italian Olympic Committee (CONI), 00197 Roma, Italy \\ 3 Department of Clinical and Experimental Medicine, Internal Medicine Division, School of Medicine, \\ University of Catania, 95100 Catania, Italy \\ * Correspondence: danielacatalano@unict.it or sum@unict.it; Tel.: +39-095-378-1533
}

Academic Editor: Giuseppe Musumeci

Received: 17 May 2016; Accepted: 2 August 2016; Published: 9 August 2016

\begin{abstract}
An overview of the relationship between elite athletes' sport activity and medicine was presented during a conference with guest speaker Mrs. Sara Simeoni, Italian Olympic Games high jump champion (one gold medal, in Moscow, and silver medals in Montreal and Los Angeles). She has had a particularly prolonged career for this type of sport activity, and her endorsement and support, since she is a recognized icon of sport excellence, is very important. This is particularly true in relevant and sensitive topics such as gender inequalities, physical exercise and sport ethics. During the conference, the relationship between nutrition, physical activity and health, in both medicine and social life, were also covered. In reality, we still find that the cultural, economic, societal and political barriers are present and, currently, in some regards, they are even stronger than in the past. The interplay between evidence-based medicine, elite athletes' training, physical fitness practice and physical exercise intervention in health and disease is still being developed. Defining methods and clarifying multidimensional outcomes should, as much as possible, be pursued, and sustainable strategies and tools should be discussed.
\end{abstract}

Keywords: gender-based medicine; women's sport; health psychology; clinical nutrition

\section{Introduction}

Gender Barriers in Sport and Medicine: Culture, Opportunities and Resources is a two day comprehensive course, consisting of $16 \mathrm{~h}$ of teaching, delivered in part by blended e-learning, the introduction for which is freely available on the web https:/ /youtu.be/TmL7LPKKZqk. The course is incorporated into the elective curriculum of Clinical Methodology, Diagnosis and Medical Physiology. It is a structured component of the elective teaching activities that characterize the curriculum and the academic life of the students of the School of Medicine and Surgery at the University of Catania. We, as speakers, presented the topics and the themes of our work and our research, and there were also presentations from Francesco Basile, the Dean of the School of Medicine and Agostino Palmeri, the Teaching Clinical Dean of the School of Medicine and Surgery. The teaching strategy follows a few elementary rules, as discussed by Guglielmo Trovato, who conceived and organized this meeting. The students were invited to read the information provided by their teacher, delivered by an online e-learning tool, and to deepen their knowledge in order to learn as much as possible about the profiles of the invited speaker. In detail, they should detect in advance what they can ask the speaker(s) according to their own personal experience and expertise. Students are encouraged and advised to 
seek several sources of information, such as books, articles, any web publication and movies in which the speaker may have participated. Watching footage of some of the available speaker's previous speeches is also useful, in order to get a good idea of what the speaker is all about and to ask well focused and challenging questions.

\subsection{Research the Speech Topic}

Even if most students are not familiar with the guest speaker's area of expertise, they should know enough about the subject of the speech to be able to understand how it is relevant to the speaker, detecting the nature of the guest speaker's contribution to the field. More specifically, in this case students were asked to find out why this particular guest speaker, Mrs. Sara Simeoni, was invited to speak, evaluating which ties, if any, the speaker has to the organization hosting the event, and if the speaker was going to give a scientific, a testimonial or an inspirational speech and why.

\subsection{Interview the Guest Speaker}

Students are encouraged to ask a variety of questions, both personal and related to the topic of the speech. They may ask anything that they are comfortable asking, and that they feel will be well-received by the speaker. The purpose is to get as much material as possible to personalize the guest speaker's presentation.

A copy of the speaker's standard speech was provided preliminarily to students, as well as a short biography. The talks, as done in the room, were abridged and tailored in order to provide a simple presentation compared to the written introduction provided to the students.

During the meeting, Francesco Basile, presented the core topics of the course (e.g., their ethical and organizational aspects). Agostino Palmeri, who is a scholar of exercise physiology, presented the fundamentals and the evidence regarding benefits and risks deriving from physical activity.

\section{The Reasons for a Special Endorsement}

It should be unnecessary to ask for any endorsement or support from an important, renowned figure (celebrity, arts, politics, sports, etc.) in fields as relevant and sensitive as gender inequalities, physical exercise and sport ethics and the relationship of nutrition, physical activity and health, in medicine and social life. Nonetheless, in reality, we find that the cultural, economic, societal and political barriers are still present and, currently, even stronger in some regards than they were before. In Italy, in 2016, for International Women's Day (available on the web https://www.youtube.com/watch?v=FsIQK36_VJ4), Sara Simeoni, along with Rita Levi Montalcini, Nobel Prizewinner for Medicine and the actress Anna Magnani, were chosen as widely recognizable and suggestive icons of women's struggle to overcome barriers and inequalities. This year, we celebrated the social, economic, cultural and political achievement of women. Yet progress has slowed in many places throughout the world, so global action is needed to accelerate gender parity. Leaders across the world are pledging to take action as champions of gender parity-not only for International Women's Day, but also for every day. Individuals are continuing to pledge support within their sphere of influence, in the world of sport and in the world of medicine, in clinics, teaching and research. Moreover, the paradigm of gender inequalities may be a fruitful model to overcome other inequalities (e.g., different skin color, economic imbalance, religious differences, as well as others).

The Olympic high jump champion, Mrs. Sara Simeoni, was the gold medalist at the XXII Olympic Games in Moscow in 1980 (Figure 1), and is the world record holder with 2.01 meters. She also participated in the Olympics in Munich, Montreal (silver medal) and Los Angeles (silver medal). Simeoni was the only woman athlete not from a communist country who was able to win an athletics gold medal in Moscow in 1980. Simeoni has struggled to regain her form in the following years, due to a series of tendon injuries. At the 1984 Olympics, Simeoni carried the Italian flag at the opening ceremony in Los Angeles. Here, she cemented her reputation as one of the greatest female high jumpers ever, in a thrilling duel with German Ulrike Meyfarth. Simeoni managed to reach the $2 \mathrm{~m}$ mark for the 
first time since 1978. The ageing Meyfarth, however, replied with a 2.02 meter jump, and Simeoni won the silver medal. Because of her long-lasting successful career and championship qualities, Mrs. Sara Simeoni is widely considered one of the best Italian female athletes ever. Subsequently, Mrs. Simeoni became a physical education teacher in middle schools, and lecturer of individual sports and athletics at the University of Chieti (Italy), a job she still does today with great social and ethical commitment.

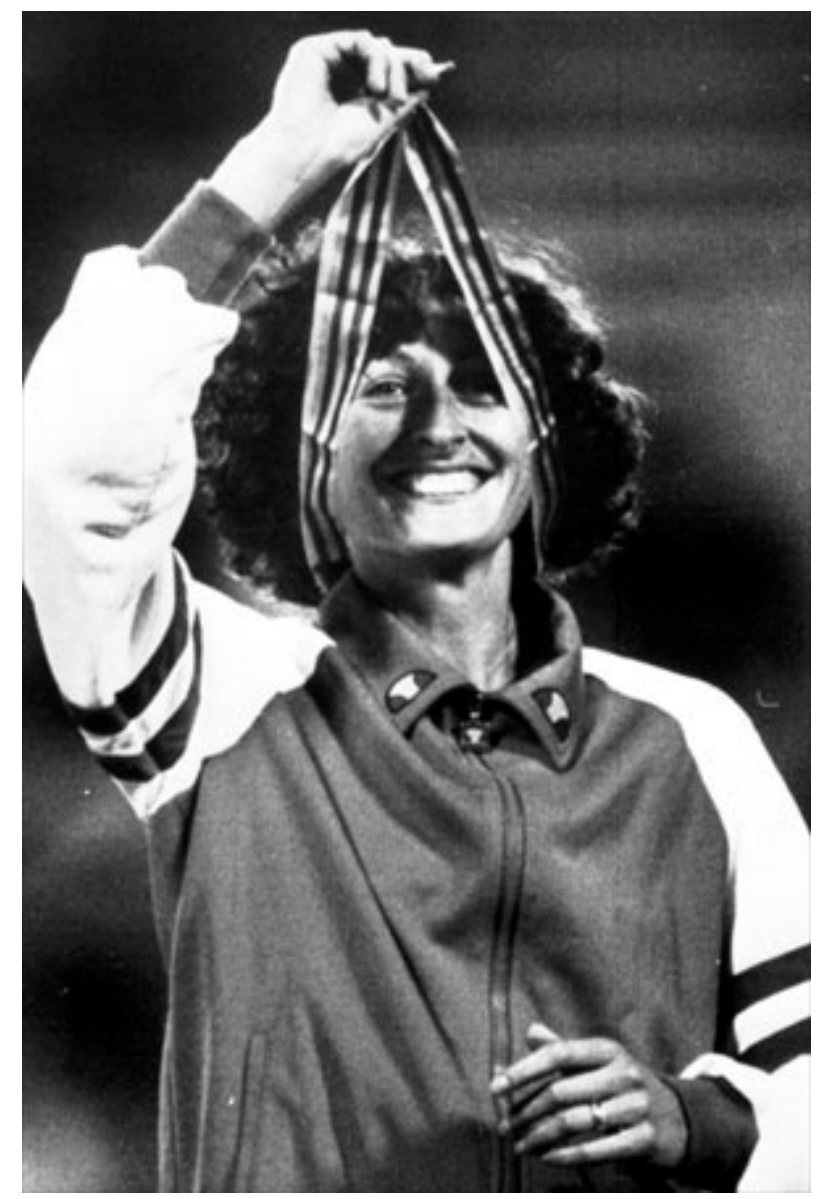

Figure 1. Mrs. Sara Simeoni, Gold Medal in high jump at the Moscow Olympic Games 1980.

\section{Exercise and Nutrition Medicine: A Hidden Niche of Our University Curricula}

In the last 20 years, also within the elective curricula planning of the School of Medicine of the University of Catania, and with European and international intervention (available on the web https: / / www.youtube.com/watch?v=bHsE1T8A0EI), Trovato, has been engaged, as he is this year, in the effort of contributing to fill the gap of reliable information and knowledge regarding nutrition and physical exercise, both in the prevention and in the treatment of diseases. In fact, there is much talk about regarding fitness and healthy diets, even before taking into account the strictly professional aspects and the cultural barriers that exist and impair an appropriate dissemination of methodologies and techniques. These discussions should be aimed at the enhancement of healthier physical activity and dietary habits and at the affordable strategies suitable to development and maintenance [1-3]. There are several inter-related determinants of human nutritional and physical exercise behavior, which are only partially individually modifiable. The context of economy, climate geography and recent and ancient history, establishes a firm and even rigid psychological and sociological basis. In addition the available data on habits, attractiveness of diet, quality of food and alimentation suffer from severe limitations and a sustainable and diffuse assessment. This should be the most consistent 
source of knowledge explored by clinical or epidemiological tools, but still we are far from a shared agreement [4-6].

Medical Doctors are too often alone with the task of personally managing prediction (early diagnosis), prevention (intervention on healthy persons) and tailored therapy and follow-up for patients (personalized medicine). In addition, the activity and awareness of participants is often only a claim that is more marketing-driven than evidence-based or supported by fact, despite the fact that this is the premise for reasonable guidelines aimed at any effective clinical practice and favorable cost-benefit balance (available on the web https://www.youtube.com/watch?v=elCgbrsxKSk).

The current demands toward healthier diet and physical exercise and fitness is also a matter of business and marketing, and is not realistically affordable. Actually, campaigns fail to sufficiently consider the real available resources of the individuals or of communities. Institutional information is appropriate but, seemingly, not particularly effective. Moreover, a global—regional, national-appraisal of the outcomes achieved by campaigns or interventions is usually lacking. Nutritional, exercise and anatomic imaging knowledge and skills teaching and training are neglected in the curricula of all schools of medicine and of allied health professions [7-9]. Moreover, we are far from the implementation of skills for enhancing healthy lifestyles, including prescribing appropriate physical activity [10]. This is due to several factors and first of all to excessive focus and expectations connected with pharmaceutical approaches. Moreover, relying on multiple specialty consultations and procedures for reaching a diagnosis and for managing patients by follow-up is a major disadvantage in terms of time, financial expenses and difficult clinical synthesis and decisions.

\section{Differences between Men and Women}

There are physiological and clinical differences between men and women that have medical relevance [11,12]. If we talk about physical activity as therapy and prevention, certainly the differences become important in prescribing physical activity; this must be related to lifestyle and in particular to choice, quality and quantity of food intake [13]. Diets, actually, are directly involved in a cyclical way with metabolism and the effects of exercise [14]. The main differences are essentially genetic, hormonal, anatomical and cultural. Only recently have doctors begun to treat health or disease conditions while considering sex and socio-economic and cultural aspects: this started the development of gender-based medicine [15-17]. Cultural barriers were and still are considerable because many scientific studies, both diagnostic and therapeutic in profile, do not take into account several peculiarities related to the sexes (Figure 2). This is even true at the ultrastructural level as well as at biochemical and morphological levels. The different motivations that drive men or women to undertake a particular type of activity are cultural. Diet is quite similar in boys and girls, at least until 12 years of age; and only thereafter are there significant changes. There is a correlation between anabolic supplements, high-protein diets and eating disorders in humans, and a great concern about addressing restrictive diets in women. This can be a form of ortorexia, which is a proposed distinct eating disorder characterized by extreme or excessive preoccupation with eating food believed to be healthy. Nevertheless, this condition, ortorexia, may also be present in men, just as mental anorexia may occur, although less frequently. In men, it is usually important to achieve a visible enhancement of muscle mass; women, frequently, are searching for a diet that keeps the body as slender as possible. Both factors may lead to unhealthy eating behavior, even inducing the exclusion of necessary nutrients. Today, fortunately, the "Mediterranean diet" is much promoted, so that there is a cost-effective, meaningful, comprehensive and sustainable goal [18]. Actually, the Mediterranean diet, if followed correctly, may be able to facilitate weight loss and encourage healthy eating, ultimately preventing cancer, atherosclerosis and cardiovascular diseases [16-19]. 


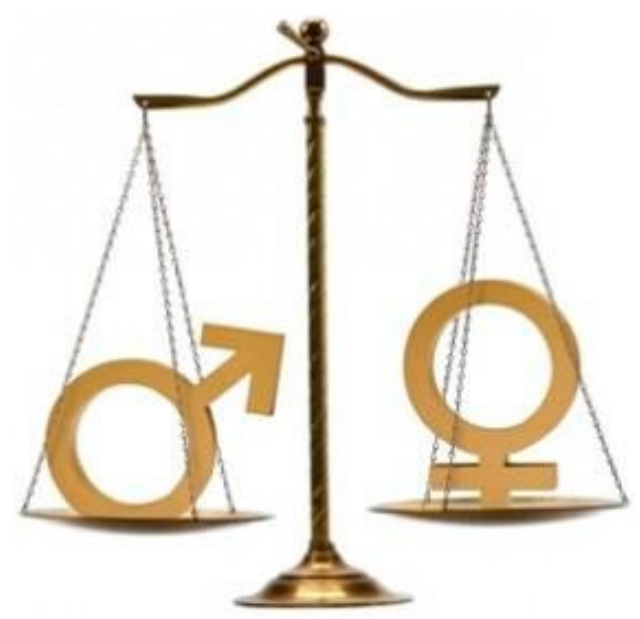

Figure 2. Equal opportunity.

The metabolic differences between men and women include muscle structure, the use of glucose, the oxidative metabolism of fatty acids and hormonal actions on the muscle. In women, there is a higher insulin sensitivity, especially in the reproductive fertile age. The muscle metabolism is also regulated by estradiol and adipokines, and, in women, metabolic response to exercise induces an increased lipolysis and a lower oxidation of glucose in the postprandial phase [20,21]. These differences can become important in the athlete's training, taking into consideration the perspective of health, wellness and disease. Gender-based medicine, however, must be managed not as a female medicine but as a medicine that takes care of the person.

\section{Mrs. Sara Simeoni Talks of Her Sports Experiences}

Gender differences can have an influence on today's sports scene and should be at the center of awareness of medicine in the treatment of sport patients.

Mrs. Simeoni's first participation in the Olympics dates back to 1972, when she was only 19 years old. Everyone was very skeptical about her capabilities. They had to think again, because Mrs. Sara Simeoni reached sixth place in the high jump. She speaks of this exciting experience, through which she had the opportunity to meet foreign opponents, realizing that the personal training that she had followed was not the most suitable for the Olympic Games and for an athlete who was preparing for winning the high jump competition (Figure 3). The culture of movement in most economically advanced countries, in contrast with Italy, starts in childhood, and accompanies the growth of children. Even today, it is a struggle in Italian schools to have an extra hour of physical education; existing structures are lacking, or worse, are not used due to human resource curtailments. Indeed, we talk too much about exercise benefit while making few concrete and verifiable efforts.

Indeed, today's SMART cities are enclosed in a technological vision and even encourage the perspective of a virtual life in the cities [22-24]. Seemingly, an explicit planning for the design and implementation of sustainable mobility contexts is lacking: this intervention should be realistically planned, with the scope of facilitating all physical mobility and, particularly, physical exercise and sports activities. There is a perverse link between lack of sustainable mobility, nightlife habits, sedentary life, malnutrition and disease in youngsters [25-27].

To return to Simeoni, in those years, 1970-1980, when several barriers were contended, one of them was "the $1.90 \mathrm{~m}$ barrier" which marked the limit beyond which women could not accomplish. Women found themselves in danger of being regarded as "aliens". It was a psychological burden, which provoked anxiety. The paradigm of marginalization that women suffer in sports is important, and is mirrored in other modes of substantial marginalization in school, work, research and social relationships. 

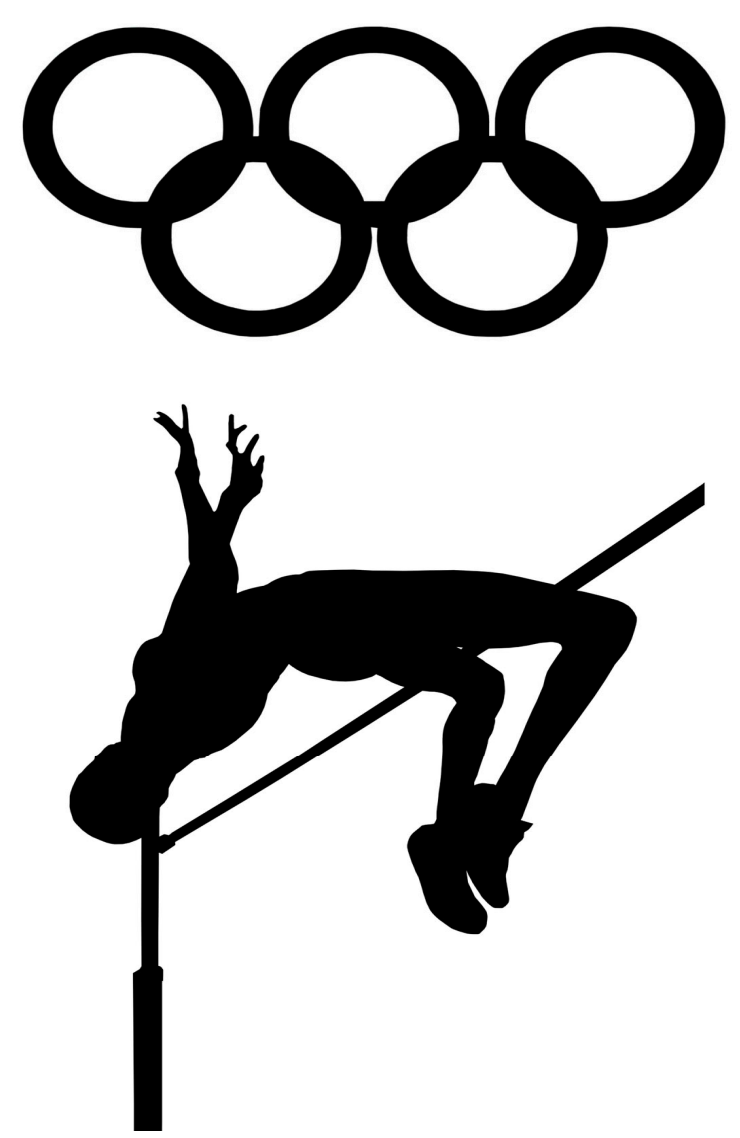

Figure 3. High Jump in Olympic Games.

There was limited availability of reliable information and knowledge on sport and gender-based medicine, with a substantial lack of evidence supported by sound scientific studies also in nutrition and physical exercise, even claiming, from epidemiological evidence, that both should be pivotal for preventing illness and treating diseases. Regretfully, there is still nowadays much talk about fitness and healthy diets, without giving due weight to strictly professional aspects and cultural barriers. These barriers exist and limit an appropriate dissemination of methodologies and techniques and strategies for changing physical activity habits and prescribing affordable health intervention.

The personal story of Mrs. Sara Simeoni is a paradigm from which excellence emerges almost by chance and in spite of a lack of routes that can promote merit and competence. Mrs. Sara Simeoni began attending the school of physical education in Bologna, and then moved to the center of Olympic training in Formia, Italy, where she found a gender-based medicine friendly and expert environment frequented by athletes who had their own and similar reasons to improve the quality of athletic training and performance. Life at the center allowed her to think about a method of training, not yet scientifically sound, but that would be more effective for achieving higher goals. The work did not end when she left the training camp, but continued outside with a lifestyle dependent on the attainment of certain objectives. Her generation did not conceive of the idea that women could practice any sport professionally. She wished to become a professional, in the years when there was no idea of professionalism in athletics. A life devoted to sport meant not being able to work, so that it was not possible to attain levels of insurance contributions that would allow for a life annuity after retirement: in fact, she decided to quit sport and began to work as a teacher in school, thus looking towards her future years.

Women have had to fight because they were considered a disturbing element to the tranquility of men, or they were, at worst a "spare tire". Their merits should be much like the function of the additional tire carried in a motor vehicle as a replacement for one that goes flat, after a blowout, or 
other emergency. All the attention was aimed at men. Even after obtaining results from the podium, female athletes were substantially ignored.

Mrs. Sara Simeoni is now happy and proud because her results and way of participating in sports have contributed in some way to making sure that women's sports and athletics are now considered differently.

\section{From an Amateur Activity to a Technical Approach}

The high jump is a track and field event in which competitors must jump unaided over a horizontal bar placed at measured heights without dislodging it. In its modern most practiced format, a bar is placed between two standards with a crash mat for landing. At the elite level, athletes run towards the bar and use the Fosbury Flop method of jumping, leaping head first with their back to the bar. Performed since ancient times, competitors have introduced increasingly more effective techniques to arrive at the current form. The high jump was among the first events deemed acceptable for women, having been held at the 1928 Olympic Games. Mrs. Sara Simeoni had to follow training that would be suitable for her age; lacking reliable guidelines, she learnt by practice, together with occasional observation of competitors and systematic observation of her own performance. Her efforts were addressed to changing and personalizing all the steps of the training. A true methodology of women's training, especially in Italy, was not in use and in part is still lacking. The only thing taken for granted was that the woman, not having the same strength as a man had to train twice as long. Adopting the new Fosbury style gave importance to the speed of the run up and the position angles during movement (Figure 4). It was a method that Mrs. Sara Simeoni investigated and pursued actively with her coach, who was then, as now, her husband Erminio Azzaro, Italian high jump champion. Those were years when physiologists began to study how the body responded to several possible or actual sport injuries [28-30]. Nutritionists tried to create specific diets for athletes, with little knowledge, some prejudice and a particular attention to the effects using clinical attitudes and awareness of the capabilities of active empowerment [31]. In this regard, there are no shortcuts, and a clinical observation of adherence to diet and of achieved effects is crucial. In the words of Mrs. Simeoni: "no one likes losing but when you lose, you examine your conscience. When you lose, when you reach the result, that's where you start to think and wonder: what have I done? I went to bed late? I drank a bit too much? Did I exaggerate? Have I not trained well? Looking for the reasons that lead you to improve, in order to avoid making same mistakes again. When you get a good result, then it will be more difficult to fall."

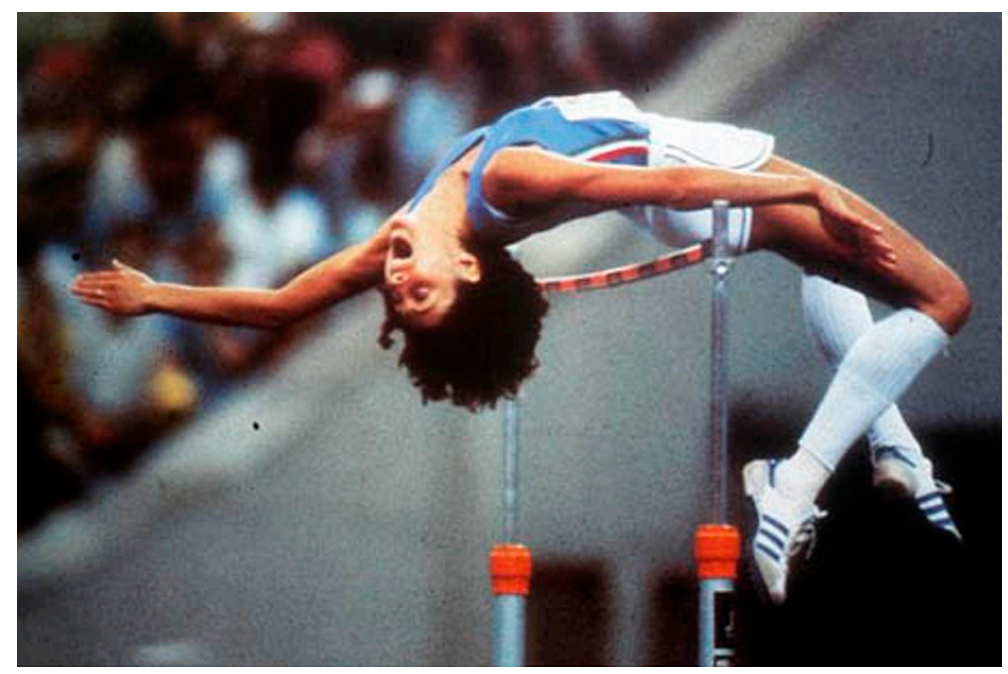

Figure 4. Mrs. Sara Simeoni's Jump, Fosbury Style. 
Media coverage for women's sports has been significantly less than the coverage for men's sports. Millions of young women from all over the world play sports every day. However, the number of women playing sports does not correspond to the amount of media coverage that they get. In addition, the problems related to the athlete's health in this, and in other disciplines, are still the object of study. Observation is leading to the awareness that all the body should be harmonically developed and trained, including the arms, even in the high jump [32]. In addition, the investigation involving gender difference in the heart's response to exercise [33,34] and other physiological responses in women [35-37] are probably fruitful fields of research, with some translational applications.

\section{The High Jump as a Paradigm of the Aims of Sports Medicine}

Over the years, the high jump has undergone a great evolution, in order to find a technique that would allow the athlete to project his or her center of gravity as high as possible and make the most of the height reached in jumping the bar. From the beginning, the old style front jump moved to the "scissors" and the "double scissor" jump, till the Horine western roll jump (with which in 1912 for the first time the barrier of 2 meters was exceeded) and to the "Fosbury", which has replaced the previous techniques thanks to indisputable biomechanical and technical benefits (Figure 5). Compared to the previous ventral style, which required greater explosive force capacity, Fosbury is more "natural" and easier to learn. Within the same technique then you can distinguish two main variants: Flop-1 more oriented to the run speed and Flop-2 more oriented to the force of the take-off. Methodology of the high jump includes an elementary sequence: the approach to the jump, and the takeoff. The approach to the high jump may actually be more important than the take-off. If a high jumper runs with bad timing or without enough aggression, clearing a high bar becomes more of a challenge. The approach requires a certain shape or curve, the right amount of speed, and the correct number of strides. The approach angle is also critical for optimal height. Most great straddle jumpers run at angles of about 30 to 40 degrees. The length of the run is determined by the speed of the person's approach. A slower run requires about 8 strides. However, a faster high jumper might need about 13 strides. A greater run speed allows a greater part of the body's forward momentum to be converted upward. The J type approach, favored by Fosbury floppers, allows for horizontal speed, the ability to turn in the air (centripetal force), and good take-off position. The approach should be a hard controlled stride so that a person does not fall from creating an angle with speed. Athletes should run tall and lean on the curve, from the ankles and not the hips. Jumpers must take off on one foot. The key feature of the Fosbury revolution is the possibility of significant adaptations to the individual characteristics of the athlete (Figure 6).

Two particular movements of the left arm and then of the free leg at the time of take-off, although being instinctive movements on Mrs. Simeoni's part, have contributed to her world record and were deliberately favored and fostered, leading to an improvement in her performance. This led other athletes to emulate this particular movement. Today everything is technological, and more advanced studies of high jump are being carried out, even in the dark. Even the use of the piezoelectric platforms, pioneered thirty years ago when it was an experimental device, today has also become a tool of study and preparation for better athletic performance.

As in any exercise activity, the training and the behavior before, during and after any single competition are the critical factors. These include, apart from the difference of jumping performance profile of male and female gymnasts [29], a great amount of care taken in terms of well-being according to general nutritional requirements, healthy sleep rhythms and avoiding other environmental annoyances. The optimization of comprehensive techniques of training and the studies on muscle and articular physiology in high jump are, overall, few and relatively recent [32,38,39]. 


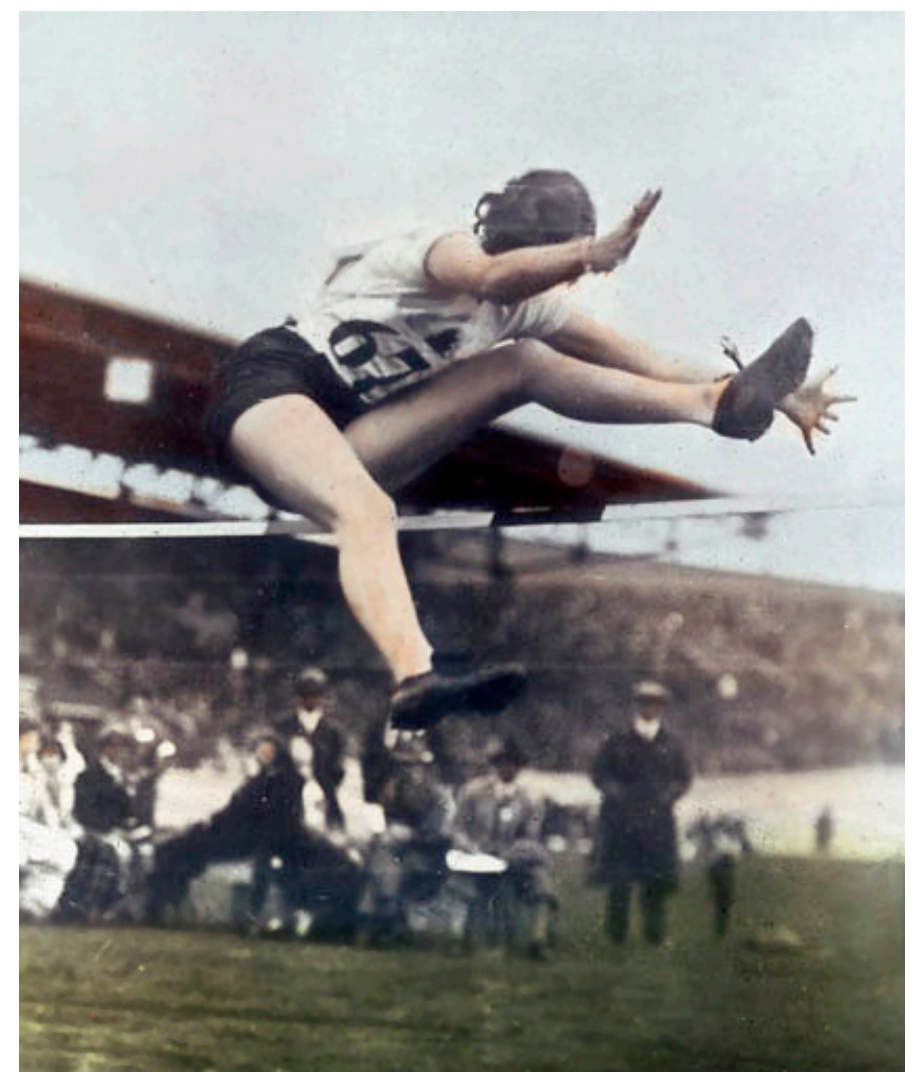

Figure 5. High Jump, scissors style.

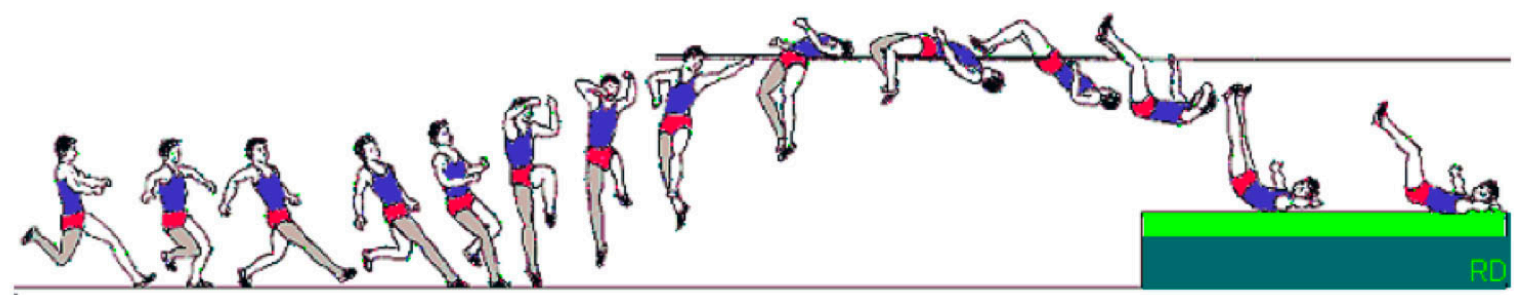

Figure 6. A sketch of the high jump, Fosbury Style.

\section{Conclusions}

The interplay between evidence based medicine, elite athletes' training, physical fitness practice and physical exercise intervention in health and disease are still patchy and in development. Definition of methods of assessment and clarity of the multidimensional desired outcomes should be pursued as much as possible. The scope of a medical-assisted training, in individual and in group activity, should encompass these main objectives:

(1) The attainment of the best possible performance in exercise goals and competition;

(2) The maintenance or the improvement of the optimal or desired physical and mental welfare;

(3) The achievement of a satisfactory health status, reducing the risk and the occurrence of disease and injuries, either directly or indirectly related to the sport activity, and, as gross outcome, assuring a greater and healthier longevity.

Acknowledgments: The authors acknowledge the substantial help of Erminio Azzaro, athletic coach of Simeoni, of our students of the School of Medicine, for their active attendance and the hosting of the School of Medicine that made possible this Course. All photographic material was provided by Mrs. Simeoni, and is available in her archive. 
Author Contributions: The authors contributed equally to this work.

Conflicts of Interest: The authors declare no conflict of interest.

\section{References}

1. Trovato, G.M. Behavior, nutrition and lifestyle in a comprehensive health and disease paradigm: Skills and knowledge for a predictive, preventive and personalized medicine. EPMA J. 2012, 3, 8-20. [CrossRef] [PubMed]

2. Trovato, G.M. Sustainable medical research by effective and comprehensive medical skills: Overcoming the frontiers by predictive, preventive and personalized medicine. EPMA J. 2014, 5, 14-26. [CrossRef] [PubMed]

3. Trovato, F.M.; Catalano, D.; Martines, G.F.; Pace, P.; Trovato, G.M. Mediterranean diet and non-alcoholic fatty liver disease: The need of extended and comprehensive interventions. Clin. Nutr. 2015, 34, 86-88. [CrossRef] [PubMed]

4. Trovato, F.M.; Martines, G.F.; Brischetto, D.; Catalano, D.; Musumeci, G.; Trovato, G.M. Fatty liver disease and lifestyle in youngsters: Diet, food intake frequency, exercise, sleep shortage and fashion. Liver Int. 2016, 36, 427-433. [CrossRef] [PubMed]

5. Catalano, D.; Trovato, G.M.; Pace, P.; Martines, G.F.; Trovato, F.M. Mediterranean diet and physical activity: An intervention study. Does olive oil exercise the body through the mind? Int. J. Cardiol. 2013, 168, 4408-4409. [CrossRef] [PubMed]

6. Trovato, G.M.; Catalano, D.; Trovato, F.M. The challenge of obesity: Can we look to the moon instead of the finger? J. Am. Coll. Cardiol. 2013, 62, 1036. [CrossRef] [PubMed]

7. Trovato, G.M.; Pace, P.; Cangemi, E.; Martines, G.F.; Trovato, F.M.; Catalano, D. Gender, lifestyles, illness perception and stress in stable atrial fibrillation. Clin. Ter. 2012, 163, 281-286. [PubMed]

8. Trovato, G.M.; Catalano, D.; Sperandeo, M. Top or Flop: The need to improve knowledge and skills achieved by Ultrasound Medical Curricula. Acad. Med. 2015, 90, 839-840. [CrossRef] [PubMed]

9. Trovato, F.M.; Musumeci, G. Lung ultrasound: The need of an adequate training for the next generation of internists. Neth. J. Med. 2015, 73, 305. [PubMed]

10. Trovato, F.M.; Catalano, D.; Musumeci, G.; Trovato, G.M. 4Ps medicine of the fatty liver: The research model of predictive, preventive, personalized and participatory medicine-recommendations for facing obesity, fatty liver and fibrosis epidemics. EPMA J. 2014, 5, 21. [CrossRef] [PubMed]

11. Braun, B.; Horton, T. Endocrine regulation of exercise substrate utilization in women compared to men. Exerc. Sport Sci. Rev. 2001, 29, 149-154. [CrossRef] [PubMed]

12. Hansen, M.; Kjaer, M. Influence of sex and estrogen on musculotendinous protein turnover at rest and after exercise. Exerc. Sport Sci. Rev. 2014, 42, 183-192. [CrossRef] [PubMed]

13. Howe, S.M.; Hand, T.M.; Manore, M.M. Exercise-trained men and women: Role of exercise and diet on appetite and energy intake. Nutrients 2014, 6, 4935-4960. [CrossRef] [PubMed]

14. Trovato, G.M.; Catalano, D.; Martines, G.F.; Pirri, C.; Trovato, F.M. Western dietary pattern and sedentary life: Independent effects of diet and physical exercise intensity on NAFLD. Am. J. Gastroenterol. 2013, 108, 1932-1933. [CrossRef] [PubMed]

15. Westenhoefer, J. Age and gender dependent profile of food choice. Forum Nutr. 2005, 57, 44-51. [PubMed]

16. Rolls, B.J.; Fedoroff, I.C.; Guthrie, J.F. Gender differences in eating behavior and body weight regulation. Health Psychol. 1991, 10, 133-142. [CrossRef] [PubMed]

17. Trovato, G.M. Mediterranean Diet-The Myth and the Truth; L\&L Press: Dutham, NC, USA, 2009; pp. 1-337.

18. Trovato, G.M.; Catalano, D.; Martines, G.F.; Pace, P.; Trovato, F.M. Mediterranean diet: Relationship with anxiety and depression. Ann. Neurol. 2014, 75, 613. [CrossRef] [PubMed]

19. Trovato, G.M.; Martines, G.F.; Trovato, F.M.; Catalano, D. Relation of the traditional Mediterranean diet to cerebrovascular disease in a Mediterranean population. Am. J. Epidemiol. 2013, 178, 661. [CrossRef] [PubMed]

20. Høeg, L.D.; Sjøberg, K.A.; Jeppesen, J.; Jensen, T.E.; Frøsig, C.; Birk, J.B.; Bisiani, B.; Hiscock, N.; Pilegaard, H.; Wojtaszewski, J.F.; et al. Lipid-induced insulin resistance affects women less than men and is not accompanied by inflammation or impaired proximal insulin signaling. Diabetes 2011, 60, 64-73. [CrossRef] [PubMed] 
21. Lundsgaard, A.M.; Kiens, B. Gender differences in skeletal muscle substrate metabolism-Molecular mechanisms and insulin sensitivity. Front. Endocrinol. (Lausanne) 2014, 5, 195. [CrossRef] [PubMed]

22. Shapira, N. Women's higher health risks in the obesogenic environment: A gender nutrition approach to metabolic dimorphism with predictive, preventive, and personalised medicine. EPMA J. 2013, 4, 1. [CrossRef] [PubMed]

23. Loptson, K.; Muhajarine, N.; Ridalls, T. Smart Cities, Healthy Kids Research Team. Walkable for whom? Examining the role of the built environment on the neighbourhood-based physical activity of children. Can. J. Public Health 2012, 103, 29-34.

24. Esliger, D.W.; Sherar, L.B.; Muhajarine, N. Smart cities, healthy kids: The association between neighbourhood design and children's physical activity and time spent sedentary. Can. J. Public Health 2012, 103, 22-28.

25. Trovato, G.; Brischetto, D.; Martines, G.F. Teens' obesity, noise and sleep deprivation: A perverse liaison. Let's move beyond "movida". Obesity 2014, 22, 1209. [CrossRef] [PubMed]

26. Trovato, G.; Brischetto, D.; Pace, P.; Martines, G.F. Perceived body weight status of youngsters interferes with headache in obese and non-obese subjects. Headache 2014, 54, 1062-1063. [CrossRef] [PubMed]

27. Trovato, G.; Pace, P.; Martines, G.F.; Brischetto, D. Mala-movida: Late bed-timing and wake-up induce malnutrition and underweight in youngsters. Chronobiol. Int. 2014, 31, 945-946. [CrossRef] [PubMed]

28. Dapena, J.; Chung, C.S. Vertical and radial motions of the body during the take-off phase of high jumping. Med. Sci. Sports Exerc. 1988, 20, 290-302. [CrossRef] [PubMed]

29. Marina, M.; Jemni, M.; Rodríguez, F. Jumping performance profile of male and female gymnasts. J. Sports Med. Phys. Fit. 2013, 53, 378-386.

30. Schmitt, H.; Dubljanin, E.; Schneider, S.; Schiltenwolf, M. Radiographic changes in the lumbar spine in former elite athletes. Spine (Phila Pa 1976) 2004, 29, 2554-2559. [CrossRef]

31. Olsson, C.J.; Jonsson, B.; Nyberg, L. Internal imagery training in active high jumpers. Scand. J. Psychol. 2008, 49, 133-140. [CrossRef] [PubMed]

32. Lees, A.; Rojas, J.; Ceperos, M.; Soto, V.; Gutierrez, M. How the free limbs are used by elite high jumpers in generating vertical velocity. Ergonomics 2000, 43, 1622-1636. [CrossRef] [PubMed]

33. Massimino, A.; Trovato, G.; Monte, I.; di Fazzio, S.; Modica, G. Vectorcardiographic changes during exercise in normal subjects. Cardiologia 1982, 27, 463-476. [PubMed]

34. Trovato, G.M.; Massimino, A.; Mammana, S.; D’Urso, V.; Vancheri, F.; Modica, G. Exercise echocardiography in normal subjects. Boll. Soc. Ital. Cardiol. 1981, 26, 2209-2223. [PubMed]

35. Holloway, J.B.; Baechle, T.R. Strength training for female athletes. A review of selected aspects. Sports Med. 1990, 9, 216-228. [CrossRef] [PubMed]

36. Carbon, R. ABC of sports medicine. Female athletes. BMJ 1994, 309, 254-258. [CrossRef] [PubMed]

37. Lewis, D.A.; Kamon, E.; Hodgson, J.L. Physiological differences between genders. Implications for sports conditioning. Sports. Med. 1986, 3, 357-369. [CrossRef] [PubMed]

38. Zamparo, P.; Minetti, A.E.; di Prampero, P.E. Interplay among the changes of muscle strength, cross-sectional area and maximal explosive power: Theory and facts. Eur. J. Appl. Physiol. 2002, 88, 193-202. [PubMed]

39. Miyaguchi, K.; Demura, S. Specific factors that influence deciding the takeoff leg during jumping movements. J. Strength Cond. Res. 2010, 24, 2516-2522. [CrossRef] [PubMed]

(C) 2016 by the authors; licensee MDPI, Basel, Switzerland. This article is an open access article distributed under the terms and conditions of the Creative Commons Attribution (CC-BY) license (http:/ / creativecommons.org/licenses/by/4.0/). 